\title{
EVALUATION OF THE 1996 CHIEF HEALTH OFFICER'S REPORT
}

Michele Puech, Gerard Fitzsimmons, Louisa Jorm Epidemiology and Surveillance Branch, NSW Health Department

This article reports on the evaluation of the 1996 Chief Health Officer's Report on the Health of the People of NSW.

The report, the first of its kind in NSW, was launched in July 1996. Its purpose was to provide a detailed account of the health status of the NSW population, with particular emphasis on priority groups. The report also emphasised health priority areas such as cardiovascular disease, cancer, mental health, injury, diabetes and asthma. It used available population health information, bringing together routinely collected data as well as data from occasional surveys and studies conducted to answer specific health questions.

A three-page evaluation questionnaire was sent early in December 1996 to chief executive officers of Area Health Services, Public Health Unit directors, health services planners, health promotion managers and managers included in the NSW Health central administration distribution mailing list. A total of 151 forms was distributed, and 71 ( 47 per cent) were returned.

\section{USE OF THE REPORT}

Only 9 per cent of respondents had not read or used the report; 71 per cent had read and/or used some of it, whereas 20 per cent had read and/or used it extensively. The most common use was as a data reference document: data were used for planning, developing Area Health Service performance agreements, developing policy, program evaluation and to answer public and media inquiries.

\section{PRESENTATION}

The ease of finding information in the report was rated "excellent" by 28 per cent of respondents and "good to OK" by another 71 per cent. Similarly, 20 per cent thought the organisation and layout were "excellent" and the other 80 per cent considered them to be "good to OK". Regarding presentation and appearance, 20 per cent judged them "excellent" and another 78 per cent "good to OK".

The number of tables was "about right" for 76 per cent of respondents, and 71 per cent thought the same for the number of figures and graphs.

The amount of verbal description of data was rated "about right" by 66 per cent of respondents. About half of the respondents thought there was the right amount of data interpretation ( 51 per cent) and breakdown by Area Health Service ( 44 per cent). However, the need for more was expressed by 35 per cent and 51 per cent, respectively.

The main suggestions made to improve the report presentation were: include a detailed index, a glossary (definitions) and a methodology section; and add a conclusion including recommendations for action.

\section{CONTENT}

General suggestions for improving the report content were to:

- give rates and confidence intervals;

- present more Area Health Service and local government area breakdowns;

- have more interstate and international comparisons and more trend data; and

- include a chapter on the information deficiencies identified in the report.

More than half the respondents ( 54 per cent) suggested that additional chapters should be included. The following were suggested more than once:

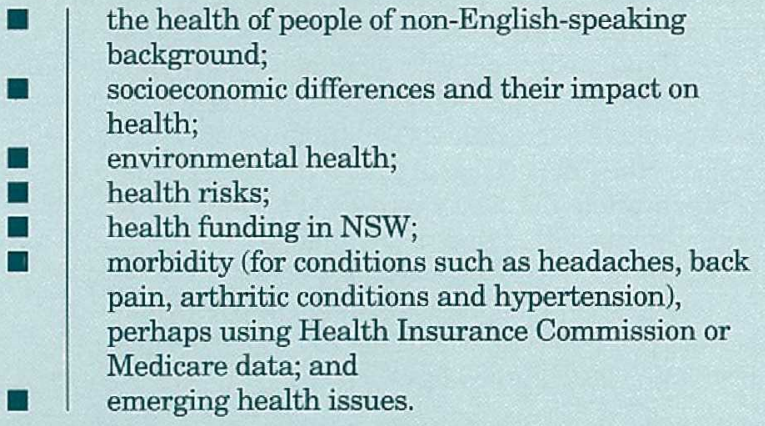

Individual issues that were felt to warrant more detailed discussion, perhaps as occasional topical chapters, included:

$\square$
$\square$
$\square$
$\square$
$\square$
$\square$
$\square$ air quality, water quality, pollution in industrial areas;

- prostate cancer screening, other screening programs; impact of influenza equity challenges; food safety; immunisation; psychological wellbeing; drugs and alcohol; rural health; and women's health and men's health.

\section{THE 1997 CHIEF HEALTH OFFICER'S REPORT}

Many of these suggestions have been incorporated into the 1997 Chief Health Officer's Report. A summary of this report will be included in a future edition of the NSW Public Health Bulletin. The chapters have been regrouped into four sections:

1. Patterns of health and illness

2. Determinants of health

3. Health inequalities

4. Health priority areas

This new edition extensively presents trend data and breakdowns by Area Health Service; rates and confidence intervals are given when possible.

Public Health Division. The Health of the People of New South Wales Report of the Chief Health Officer. Sydney: NSW Health Department, 1996.

Copies of the report are available from the NSW Health Department website at www health nsw gov,au/public-health/chorep/chorep.html. Further details of the evaluation are available on request from

Further details of the evaluation are available on request from Gerard Fitzsimmons, Epidemiology and Surveillance Branch, NSW
Health Department, Locked Mail Bag 961, North Sydney NSW 2059. 